\title{
1 Blood Digestion by Trypsin-Like Serine Protease in the Replete Lyme Disease
}

\section{Vector Tick, Ixodes scapularis}

3 Jeremiah Reyes ${ }^{1}$, Cuauhtemoc Ayala-Chavez ${ }^{1}$, Michael Pham ${ }^{1}$, Arvind Sharma ${ }^{1}$ Andrew

$4 \quad$ Nuss $^{1,2^{*}}$, Monika Gulia-Nuss ${ }^{1, *}$

$5 \quad{ }^{1}$ Department of Biochemistry and Molecular Biology

$6 \quad{ }^{2}$ Department of Agriculture, Veterinary, and Rangeland Sciences

7 University of Nevada, Reno, Reno, NV, 89557, USA

8 *Corresponding authors; nuss@cabnr.unr.edu; mgulianuss@unr.edu

\section{ABSTRACT}

Ixodes scapularis is the major vector of Lyme disease in the eastern United States.

12 Each active life stage (larva, nymph, and adult) takes a blood meal either for developing

13 and molting to the next stage (larvae and nymphs) or for oviposition (adult females). This

14 protein-rich blood meal is the only food taken by Ixodes ticks and therefore blood

15 digestion is very important for tick survival. Most studies on blood digestion in ticks have

16 shown that the initial stages of digestion are carried out by cathepsin proteases within

17 acidic digestive cells. However, most of these studies have focused on partially engorged

18 ticks. In other hematophagous arthropods, the serine proteases play an important role in

19 blood protein degradation. In this study, we determined transcript expression of four $I$.

20 scapularis serine proteases with previously characterized roles in blood digestion. RNA

21 interference was used for functional analysis and a trypsin-benzoyl-D, L-arginine 4- 
22 nitoanilide assay was used to measure active trypsin levels. An in vitro hemoglobinolytic

23 assay was performed with or without serine protease inhibitor. Our data suggest that

24 trypsin levels increase significantly after blood feeding and peaked in larvae, nymphs,

25 and adults at 3,1, and 1 day post host detachment, respectively. The knockdown of three

26 previously identified serine proteases by RNAi negatively impacted blood intake,

27 survival, fecundity, levels of active trypsin in the gut and resulted in lower hemoglobin

28 degradation in vitro. A trypsin inhibitor, PMSF, blocked the action of trypsin in the gut

29 extract resulting in $65 \%$ lower hemoglobin degradation. We provide evidence of the

30 serine proteases as digestive enzymes in fully engorged, replete females. Our data also

31 demonstrated that in addition to blood digestion, these serine proteases might have a role

32 in blood feeding success in I. scapularis.

33 Key words: Ticks, Ixodes scapularis, serine protease, blood digestion, trypsin

\section{INTRODUCTION}

Ixodes scapularis is a three-host tick that requires a blood meal to complete each

37 and nymphs feed for 3-7 days whereas adult female feeding lasts for up to 10 days and

38 consists of (i) a slow feeding period up to 5-9 days post attachment followed by (ii) rapid

39 engorgement for 12-24 h before detachment from the host [2]. Rapid engorgement

40 accounts for about two-thirds of the total blood meal. The tick gut comprises a major

41 portion of the body and consists of a ventriculus (stomach) and several pairs of highly

42 branched ceca extending into all regions of the body. Blood digestion putatively starts in

43 the gut soon after ingestion and continues for several days to weeks after dropping off the

44 host. Proteins represent about $95 \%$ of the non-water content of vertebrate blood. 
45 Consequently, hematophagous arthropods require proteases as the main enzymes in the

46 midgut to process a blood meal [3].

A typical animal genome contains $2-4 \%$ of genes encoding for proteolytic enzymes [4]. Among these, serine proteases are the most abundant and functionally

49 diverse group [5]. Over one-third of all known proteolytic enzymes are serine proteases.

50 Out of a total of 233 putatively active I. scapularis proteases thus far identified, 63 (27\%)

51 are serine proteases [3]. Hematophagous insects such as tsetse flies, mosquitoes, and

52 many other insects digest the protein-rich blood meal mainly by using trypsin-like serine

53 proteases that have a $\mathrm{pH}$ optimum in the alkaline range $(\sim 8.0 \mathrm{pH})$ [6]. Processing of host

54 blood components in tick midgut, however, appears to differ greatly from that in other

55 hematophagous arthropods. In ticks, blood digestion is a slow process that has been

56 shown to occur in the acidic environment of gut intracellular vesicles (endosomes),

57 mainly by the cathepsin-like proteases [3]. In hematophagous insects, in contrast, protein

58 digestion proceeds rapidly and takes place in the gut lumen.

A multi-enzyme model for hemoglobin degradation was proposed for the

60 European vector of Lyme disease, the castor bean tick, I. Ricinus [7]. According to this

61 model, the hemoglobin degradation pathway is initiated inside the acidic digestive vesicle

62 by cysteine and aspartic endopeptidases (cathepsin L, legumain, and cathepsin D),

63 generating large peptide fragments $(8-11 \mathrm{kDa})$, followed by the action of cathepsin $\mathrm{B}$ and

64 C exopeptidases, generating smaller peptides $(2-7 \mathrm{kDa})$. Finally, serine carboxypeptidase

65 (SCP, SP28 subfamily) and leucine aminopeptidase may participate in the liberation of

66 dipeptides and free amino acids. Other studies have suggested that the final stages of

67 hemoglobin degradation take place both in and outside of the digestive vesicles [8]. 
68 Trypsin serine proteases are active at high $\mathrm{pH}$ [9], in contrast to the acidic-active

69 cathepsins. Midgut homogenates of the hard tick, I. scapularis (formerly I. dammini),

70 were shown to lyse erythrocytes from different vertebrates blood at an alkaline $\mathrm{pH}$

71 suggesting the involvement of trypsin enzymes. Ten major blood digestive proteases

72 (cathepsin, aminopeptidase, and serine proteases) were proposed to be involved in blood

73 digestion in I. scapularis [2]. The presence of four serine proteases on this list suggests

74 previously unexplored roles of trypsin during Ixodes blood ingestion.

Most studies in tick blood digestion have focused on partially engorged females

76 (up to 5 days on host, slow feeding phase), resulting in little information on the digestive

77 profile beyond this stage. Therefore, to better understand the digestive enzyme profile of

78 I. scapularis, we first tested expression of ten proteases identified previously [2] and then

79 measured trypsin activity in unfed, partially fed, and post host detachment ticks up to 7

80 days (adults) and 28 days (larvae and nymphs) using benzoyl-D, L-arginine 4-nitroanilide

81 (BApNA), a trypsin-specific substrate [10-11]. Our results suggest that tick serine

82 proteases are active within $24 \mathrm{~h}$ post host detachment (replete) and may play a major,

83 previously unrecognized, role in early blood digestion in all tick life stages.

84 Understanding the digestive profile of trypsin during blood meal digestion in $I$.

85 scapularis improves our understanding of the basic biology of ticks and may lead to new

86 methods for tick control.

\section{METHODS}

88 Tick samples: Pathogen free I. scapularis were acquired from the tick rearing facility at

89 Oklahoma State University, Stillwater, OK. Ticks were then transferred to an incubator

90 and kept at $95 \%$ relative humidity and $20^{\circ} \mathrm{C}$ in our laboratory. 
91 Blood feeding: Unfed larvae and nymphs were fed on mice at the University of Nevada,

92 Reno. Both stages were allowed to detach naturally post engorgement. Once detached,

93 the ticks were collected as soon as possible and returned to the incubator and harvested at

94 the appropriate post blood meal intervals. All procedures were approved by the

95 Institutional Animal Care and Use Committee (IACUC) at the University of Nevada,

96 Reno (IACUC \# 00682). Adults were purchased from the Oklahoma University,

97 Stillwater, OK, Tick rearing facility.

98 Sample collection: Larvae and nymphs were collected at day 1, 2, 3, 7, 14, 21, and 28

99 days post engorgement/ host detachment (repletion). Two larvae or nymphs per sample

100 were collected in triplicate for each time point.

Adult females were collected at 5 days post host attachment (partially fed), and at

$1021,2,3,7$, and 14 days post engorgement/host detachment (replete). Whole guts were

103 dissected and two guts were pooled per sample. Experiments were replicated with three

104 biological cohorts. For unfed samples, four guts were pooled. Midguts were dissected in

105 cold PBS buffer and rinsed with PBS to remove the blood. Once cleaned of blood,

106 midguts were immediately transferred to either a cold $1.7 \mathrm{ml}$ tube containing $200 \mu \mathrm{l}$ of

107 Trizol or Tris- $\mathrm{HCl}-\mathrm{CaCl}_{2}$ and stored at $-80^{\circ} \mathrm{C}$ until processed.

108 RT-PCR: Midguts were collected from adult females in Trizol reagent (Invitrogen) as

109 described above. Total RNA was extracted using Trizol reagent and a Zymo Directzol kit

110 (Zymo Research, Irvine, California). Total RNA was DNase treated before using for

111 cDNA synthesis. $1 \mu \mathrm{g}$ DNAse-treated RNA was used for cDNA synthesis (iScript,

112 BioRad, CA). For RT-PCR, $1 \mu \mathrm{l}$ of 1:10 diluted cDNA was used as a template in a $20 \mu \mathrm{l}$

113 reaction. RT-PCR conditions for all four serine proteases were: Initial denaturation at 
$11495^{\circ} \mathrm{C}$ for $5 \mathrm{~min}, 95^{\circ} \mathrm{C}$ for $30 \mathrm{sec}, 55-58^{\circ} \mathrm{C}$ for $30 \mathrm{sec}$ (Table 1 ), $72^{\circ} \mathrm{C}$ for $30 \mathrm{sec}$, repeated 115 for 35 cycles and a final extension at $72^{\circ} \mathrm{C}$ for $10 \mathrm{~min} .10 \mu \mathrm{l}$ of the reaction was separated

116 by electrophoresis on a $1.2 \%$ agarose gel along with the DNA ladder (Apex DNA Ladder

117 II; Genesee) and visualized by using Amresco ethidium bromide free dye (Amresco).

118 Primer sequences for all proteases are listed in Table 1. Tubulin was used as a

119 housekeeping control [12].

Gel images were visualized and band intensity was analyzed by densitometry

121 using Image Lab 5.2.1 (Gel Doc EZ-Imager, BioRad). The DNA ladder was used as the

122 standard for generating a linear regression model to determine PCR product abundance.

123 The ratio of the tubulin control band intensity was used to standardize the values of the

124 band from each gene at different time points.

125 Sample Preparation for BApNA assay: Six larvae or nymphs from each post blood meal

126 time point were collected in triplicates (two individuals per triplicate). Samples were

127 sonicated in $100 \mu \mathrm{l}$ Tris-HCl- $\mathrm{CaCl}_{2}$ buffer until completely homogenized and centrifuged

128 at $12,000 \mathrm{RPM}$ for $5 \mathrm{~min}$ at $4^{\circ} \mathrm{C}$. The supernatants from each individual sample were

129 transferred to clean $1.7 \mathrm{ml}$ tubes. $10 \mu \mathrm{l}$ supernatant from each sample was added to $90 \mu \mathrm{l}$

130 of Tris-HCl-CaCl $\mathrm{Cl}_{2}$ [11]. Finally, $200 \mu \mathrm{l}$ of $4 \mathrm{mM}$ BApNA was added to the samples.

131 Samples were then placed on a shaker for $15 \mathrm{~min}$ at $25^{\circ} \mathrm{C}$, and loaded onto a 96 well plate

132 (100 $\mu 1$ sample per well).

133 Midguts were dissected and pooled from two adult females per sample and samples were 134 prepared in a similar manner as described above. Trypsin (Sigma) was used to make a

135 standard curve. Trypsin, in the presence of BApNA, cleaves p-nitroanliline off BApNA, 136 yielding a yellow substrate that was measured at $405 \mathrm{~nm}$. This is a trypsin-specific 
137 reaction that does not occur with cathepsins or chymotrypsin or other known digestive

138 enzymes [13].

139 RNA interference (RNAi): dsRNA was synthesized for three serine proteases: SP1

140 (ISCW021184), SP2 (ISCW006427), and SP4 (ISCW007492). Total RNA was extracted

141 from unfed or one-day post host detachment tick guts using Trizol reagent and Zymo

142 Directzol kit. DNAse treated RNA was used as the template for cDNA synthesis as

143 described above. Primers were designed with a T7 promoter sequence on the 5' end of

144 both forward and reverse primers (Table 1). RT-PCR conditions were the same as

145 mentioned above in the RT-PCR section. PCR products were run on a 1.2\% agarose gel.

146 Bands were extracted from the gel using the QIAquick gel extraction kit (Qiagen) and

147 used as a template for dsRNA synthesis using T7 Megascript kit (Invitrogen, CA). Newly

148 synthesized dsRNA was purified using phenol-chloroform and ethanol precipitated.

149 Sixteen unfed adult female ticks per gene were injected with $1 \mu \mathrm{L}$ of dsRNA $(2 \mu \mathrm{g} / \mu \mathrm{L})$.

150 Injections were performed with a u-200 insulin syringe on the ventral right side between

151 the $3^{\text {rd }}$ and $4^{\text {th }}$ leg of the tick. Control ticks were injected with $1 \mu$ l of

152 RNase/DNase/Protease free water (11 ticks). Control and RNAi ticks were immediately

153 placed in a holding container at $95 \% \mathrm{RH}$ and observed for $2 \mathrm{~h}$ for recovery before

154 storage. Ticks were allowed to recover for 7 days before placing on New Zealand white

155 rabbits. Ticks were confined in capsules attached to the rabbit's back using Lamar

156 adhesive and were allowed to feed to repletion. Capsules were made of 1.5 inch PVC

157 tube with a Styrofoam lip attached to side going on the rabbit. Dropped off ticks were

158 collected daily, weighed and photographed immediately after dropping off and stored in

159 individual containers in an incubator at $20^{\circ} \mathrm{C}$ and $95 \% \mathrm{RH}$. A batch of females was kept 
160 for fecundity assessment. Females were observed daily for mortality and egg-laying. Egg 161 mass was weighed once females stopped laying eggs.

162 For BApNA assay, six RNAi adult females from each of the three serine proteases were 163 collected 1-day post drop off/repletion. Control ticks were collected at the same time.

164 Two guts per sample were dissected $(\mathrm{N}=3)$ and the assay was carried out as described 165 above.

166 Hemoglobin degradation assay: Midguts were dissected individually from control and 167 RNAi females collected one-day post host detachment (hereafter post blood meal; PBM), 168 washed, and homogenized with a pestle in $0.1 \mathrm{M} \mathrm{Na}$-acetate, $1 \%$ CHAPS, and $2.5 \mathrm{mM}$ 169 DTT [8]. The gut extracts were centrifuged at $16000 \mathrm{~g}$ for $10 \mathrm{~min}$ at $4^{\circ} \mathrm{C}$ and filtered with 170 a $0.22 \mu \mathrm{M}$ Polyethersulfone (PES) membrane syringe filter (Olympus). Protein 171 concentration was measured using the BCA protein assay kit (Thermo Fisher, MA). The 172 gut protein extracts were stored at $-80^{\circ} \mathrm{C}$ until used for assays. $0.5 \mu$ g protein extract was 173 used to digest $10 \mu \mathrm{g}$ of bovine hemoglobin in $25 \mathrm{mM} \mathrm{Na}$-citrate-phosphate (pH 7.5), $1742.5 \mathrm{mM}$ DTT, and 25mM NaCl. Bovine trypsin (Sigma, MO) was used as a control for

175 hemoglobin digestion. Aliquots were taken out at 0, 10, 20, and $30 \mathrm{~min} .0 .03 \%$

176 fluorescamine (Biotium, CA) in acetone was added to the gut extract-hemoglobin 177 reaction to quantify the newly formed amino-terminal ends [14]. Fluorescence was 178 measured using the Spectramax M5 microplate reader at an excitation of $370 \mathrm{~nm}$ and 179 emission of $485 \mathrm{~nm}$ wavelengths. Measurements were performed in triplicate. For trypsin 180 activity inhibition, gut extracts were pre-incubated with 0.1mM PMSF (Research 181 Products International, IL) for $15 \mathrm{~min}$ at $37^{\circ} \mathrm{C}$ before adding hemoglobin. 
182 Statistical Analysis: All experiments were replicated a minimum of three times with 183 different biological cohorts. One-way ANOVA and Dunnet's multiple comparisons were 184 used for statistical analysis. Data from each biological replicate were combined and 185 significance was calculated using Graph Pad software.

186

187 RESULTS:

188 Transcript expression: Transcripts of 10 proteases identified as the main proteolytic 189 enzymes for hemoglobin degradation in I. scapularis [2] were examined in the adult 190 female midgut. Out of these 10, four were serine proteases (ISCW021184, ISCW006427, 191 ISCW010371, and ISCW007492), two cathepsin L (ISCW024899 and ISCW000076), 192 and one each of cathepsin C (ISCW03494), cathepsin D (ISCW023880), legumain 193 (ISCW015983), and leucine aminopeptidase (ISCW023735). All sequences were 194 confirmed by Sanger sequencing. Expression was determined at different time points: 195 partially engorged adult females (collected 5 days post host attachment but before rapid 196 engorgement), and at 1, 2, 7, and 14 days post host detachment (fully engorged and 197 actively digesting blood to provision developing eggs). Out of 10 genes tested, six were 198 expressed in unfed samples whereas four genes (ISCW023880, ISCW024899, 199 ISCW007492, and ISCW023735) were only expressed during feeding or PBM (Fig. 1 A200 B). Cathepsin D expression was highest at day 1 PBM and decreased afterward. One out 201 of two cathepsin L paralogues (ISCW024899) expressed in all blood-fed stages tested, 202 from partially fed to 14 days PBM and the other cathepsin L (ISCW000076) expressed in 203 unfed and partially fed females with almost no expression in fully engorged females.

204 Legumain was expressed at low levels in unfed females, then expression increased during 
and after feeding. Cathepsin $\mathrm{C}$ also expressed at low levels in unfed females and expression was higher during and after a blood meal; peak expression was at 2 and $7 \mathrm{D}$

PBM and decreased at day 14 PBM. Serine proteases 1 and 2 (SP 1 and 2; ISCW021184 and ISCW006427) had a similar expression pattern to one another where both expressed in unfed and partially fed females and then expression was undetectable until day 14

210 PBM. Serine protease 3 (SP3; ISCW010371) had low expression in unfed and day 14

211 PBM samples. Serine protease 4 (SP4; ISCW007492) was not detected in unfed females,

212 but the expression was detected during and after blood-feeding with the highest

213 expression in 1 D PBM samples. Leucine aminopeptidase expression was not detected in

214 unfed females and peak expression was noticed at partially engorged time point.

215 Expression decreased afterward and no expression was detected at day 14 PBM (Fig. 1 216 A-B).

217 Active trypsin in tick life stages: Trypsin activity increased significantly in larvae after

218 a blood meal (Fig. 2 A). The peak trypsin activity period was 1-3 days PBM and levels 219 decreased gradually afterward to nearly unfed levels at 21-28 days PBM (Fig. 2 A). In 220 our colony, larvae begin molting into nymphs within 3-4 weeks; therefore, the 28 day 221 time-point coincides with molting.

222 In nymphs, a similar pattern to larvae was observed. Trypsin levels increased after a 223 blood meal and were highest at 3 days PBM. Subsequently, levels decreased and by 28 224 days trypsin levels were similar to unfed controls (Fig. 2B).

225 In adult midguts, no trypsin activity was detected in unfed or partially fed ticks. Trypsin 226 activity was highest after drop off from the host (1 D PBM) and decreased gradually. By 22714 D PBM, trypsin activity returned to unfed levels (Fig. 2C). Under our rearing 
228 conditions, ticks start laying eggs 7 days PBM; therefore, most blood digestion occurs

229 during the first two weeks post host detachment.

230 Effect of serine proteases RNAi on tick blood-feeding and physiology: We attempted

231 to knock down all four serine proteases (Fig. 1); however, we could not get sufficient

232 concentrations of SP3 dsRNA. Therefore, we knockdown three serine proteases (SP1,

233 SP2, and SP4). All three serine proteases were knockdown until at least two days PBM

234 (Fig. 3A). Serine proteases knockdown resulted in a significantly lower volume of blood

235 ingested as indicated by the engorgement weight. Control females weighed 200 mg

236 whereas, SP1 knockdown weighed $140 \mathrm{mg}$, accounting for a $29 \%$ reduction in weight.

237 SP2 knockdown females weighed $\sim 110 \mathrm{mg}$ (45\% reduction) and SP4 knockdown

238 weighed $\sim 78 \mathrm{mg}$ (61\% reduction in weight) (Fig $3 \mathrm{~B}$ ).

239 Serine protease RNAi also resulted in higher mortality in ticks. About $20 \%$ of ticks died

240 in all treatments during the recovery period post-injection. Once attached to the host, all

241 control ticks fed to repletion whereas, two SP1 RNAi, and six each of SP2 and SP4 RNAi

242 ticks died between day-2 and day-5 post attachment (Fig. 3C).

243 Serine protease knockdown ticks had reduced fecundity as indicated by the egg mass

244 weight. The egg clutch weight in controls was $\sim 100 \mathrm{mg}$ whereas it reduced to $54 \mathrm{mg}$ in

245 SP1 and $22 \mathrm{mg}$ in SP4. SP2 RNAi female did not produce any eggs (Fig. 3D). These data

246 are very interesting; however, a small sample size (3 control females, 5 SP1 RNAi

247 females, and one each for SP2 and SP4 RNAi), requires further validation especially for 248 SP2 and SP4 RNAi. 
249 There was significantly less overall active trypsin in the gut in RNAi females compared

250 to the control at day-1 PBM (peak trypsin activity). The control ticks had $\sim 400 \mathrm{mg}$

251 trypsin compared to 95 (76\% reduction), 240 (40\% reduction), and $140 \mathrm{mg}$ (65\%

252 reduction) in SP1, SP2, and SP4 RNAi females, respectively (Fig. 3E).

253 Hemoglobin degradation by tick gut extract in vitro: Bovine hemoglobin incubated

254 with tick gut extracts at $7.5 \mathrm{pH}$ resulted in free amino-terminal ends indicative of

255 hemoglobin digestion by the gut extract. Serine protease RNAi decreased this activity

256 further suggesting that these proteases are involved in hemoglobin degradation and

257 therefore blood digestion. SP1 and SP2 knockdown resulted in significantly different

258 hemolytic activity compared to the control at 30 minutes; however, there was no

259 significant difference at 10 and 20 minutes (Fig. 4A). At 30 minutes incubation, SP1 and

260 SP2 knockdown resulted in 29 and $25 \%$ reduction in hemoglobin breakdown activity

261 (fluorescent activity), respectively. SP4 knockdown had the greatest effect on

262 hemoglobin breakdown and the activity differed significantly from the control starting at

26310 minutes and resulted in a $52 \%$ reduction in gut extract hemolytic activity at 30-min.

264 incubation (Fig. 4 A).

265 To confirm the trypsin-like protease activity in the gut tissue extract of fully engorged

266 tick females, we incubated gut extract from water injected ticks with a trypsin inhibitor,

267 PMSF, prior to addition of hemoglobin. Gut extract without PMSF incubation was used

268 as a control. Incubation with PMSF inhibited the gut extract activity by $55 \%$. The

269 hemoglobin degradation activity was significantly lower in PMSF incubated samples

270 starting from 10 minutes, and it was more evident at 30 minutes as there was no increase 
271 in activity with time as opposed to the gut sample without pre-incubation with PMSF

272 (Fig. 4B).

\section{DISCUSSION}

In the present work, we examined I. scapularis midgut proteases expression

275 including four trypsin-like serine protease transcripts. These serine proteases had a

276 different temporal expression: two were expressed in unfed and partially engorged

277 females, one only in unfed, and one in all blood-feeding stages tested but not in unfed

278 guts (Fig. 1A). Since transcript abundance is not a measure of enzyme activity and higher

279 transcript does not always result in translation, we measured active trypsin levels. Our

280 trypsin assay showed that unfed ticks midguts did not have trypsin activity (Fig. 2C).

281 However, trypsin activity increases after detachment from the vertebrate host and peaks

282 at 1-3 days post detachment in all life stages (Fig. 2A-C). In Aedes aegypti mosquitoes,

283 induction of trypsin biosynthesis after the blood meal is a two-phase process. The first

284 phase of trypsin biosynthesis involves the translation of an mRNA transcript that is

285 already there producing early trypsin. The second phase, $7-9 \mathrm{~h}$ after the blood meal, is

286 activated by the synthesis of a new mRNA transcript that codes for late trypsin [15]. Our

287 transcript and enzyme activity data suggest that like mosquito early trypsin, the mRNA

288 for I. scapularis trypsin is already there.

Most previous studies have focused on the mechanism of hemoglobin degradation

290 in ticks during early stages of feeding and suggested that when ticks are actively feeding

291 on the host, the main peptidases for hemoglobin digestion are: (1) clan CA cathepsins B,

292 C, and L; (2) clan CD asparaginyl endopeptidase (legumain); and (3) clan AA cathepsin

293 D. Other activities detected were attributed to monopeptidases, namely a serine 
294 carboxypeptidase and a leucine metallo-aminopeptidase within gut digestive vesicles

295 [16]. Previous studies have also suggested hemoglobin receptor-mediated endocytosis [6,

296 16] occurs in the digestive vesicles. Digestive vesicles then lead to further breakdown of

297 these peptides by creating an acidic environment suitable for cathepsin and legumain

298 activity. However, in this study, we investigated blood digestion after repletion and off

299 host, the stage that has not yet investigated. Our data strongly suggest that serine

300 proteases are involved in blood digestion in the post repletion phase. Midgut extract was

301 able to lyse hemoglobin in vitro and pre-incubation with trypsin inhibitor reduced this

302 hemolysis activity (Fig. 4A, B). The knockdown of three serine proteases individually

303 resulted in lower levels of active trypsin in BApNA assay (Fig. 3E). Serine protease

304 knockdown also resulted in reduced hemoglobin degradation activity in vitro (Fig. 4A).

305 Other studies in replete ticks have also suggested that trypsin proteases might be involved

306 in blood digestion in replete ticks. Ribeiro [17] showed that midgut homogenates of $I$.

307 scapularis, (formerly I. dammini) lysed erythrocytes from rabbits, rats, hamsters, and

308 guinea pigs. The midgut homogenate activity was optimal at an alkaline $\mathrm{pH}$, suggestive

309 of trypsin-like serine proteases. This activity was not detected in unfed ticks as well as

310 ticks attached for up to 2 days to a host and increased during the latter phase of feeding.

311 Ribeiro [17] hypothesized that this activity helped the initial process of the blood meal

312 digestion by releasing the contents of erythrocytes for further enzymatic hydrolysis,

313 possibly in the digestive vesicles. Two serine proteases in Haemaphysalis longicornis

314 ticks were identified and characterized, and expression of both serine proteases was

315 induced by blood-feeding [18]. In another study, two genes encoding trypsin-like serine

316 proteases, $H I S P 2$ and $H I S P 3$, in $H$. longicornis were also proposed to be involved in 
317 blood digestion [19]. One of these HISP genes was further characterized and was found

318 to be secreted in the gut lumen [20]. A previous report also demonstrated that hemolysin-

319 like material was present in the midgut lumen of ixodid ticks [21]. Disruption of HISP-

320 specific mRNA by RNAi resulted in inhibition of the degradation of host erythrocyte

321 membranes, indicating that HISP plays a crucial role in the hemolysis in the midgut of

322 ticks [20]. An RNAseq study comparing blood-fed and serum-fed I. ricinus midgut

323 transcriptome showed that the number of genes encoding serine proteases were markedly

324 up-regulated in the late stage of feeding [22] and a possibility of active serine proteases

325 during the off-host stage of blood digestion was suggested. Given these data in other tick

326 species and our results in I. scapularis, we propose a modified model of blood digestion

327 in ticks (Fig. 5). We suggest that blood digestion occurs in digestive cells by cathepsins

328 and aminopeptidases during the early digestive phase when the tick is still feeding,

329 whereas, in replete females trypsin-like serine proteases are important for degradation of

330 blood proteins and digestion might take place in both the gut lumen and digestive

331 vesicles. However, the latter need to be investigated in the replete ticks.

A remarkable property of certain insect guts is a very high luminal $\mathrm{pH}$, especially

333 in lepidopteran larvae ( $\mathrm{pH} 9-12)$. Whereas the mosquito, Ae. aegypti, the midgut has an

334 acidic $\mathrm{pH}$ (6.0) before a blood meal, the $\mathrm{pH}$ increases to an alkaline range (7.5) after a

335 blood meal [18]. The $\mathrm{pH}$ of the guts of mites also strongly affects their digestive

336 processes. For instance, the gut contents of acaridid mites ranged from pH 4 to 7 [24]. All

337 the assays in this study were carried out at pH 7.5 (BApNA, Hemoglobin degradation)

338 suggesting that these serine proteases are active at an alkaline $\mathrm{pH}$ and provide indirect

339 evidence of an alkaline gut lumen environment. The I. ricinus midgut homogenate 
340 activity was also optimal at an alkaline $\mathrm{pH}$ [17]. Another study found that a recombinant

341 HISP enzyme was active at pH 6.0 in H. longicornis [20]. We attempted to measure pH

342 by homogenizing guts and using a universal $\mathrm{pH}$ paper (data not shown); however, a

343 refined method of measurement is needed. For instance, the $\mathrm{pH}$ in guts of 12 species of

344 the stored product and house dust mites was determined based on the color changes of $\mathrm{pH}$

345 indicators fed to the organisms and looking at $\mathrm{pH}$ change microscopically. Unfortunately,

346 this is not feasible with ticks due to the dark cuticle and blood meal coloration. However,

347 microelectrodes are frequently used to determine gut $\mathrm{pH}$ in insects [25-28], and we plan

348 to utilize these in future experiments.

The knockdown of three serine proteases resulted in ingestion of lower blood

350 volume (Fig. 3B) that correlates with lower fecundity (Fig. D). High mortality in SP2 and

351 SP4 knockdown females post attachment (Fig. 3C) combined with reduced feeding

352 suggest their additional roles in tick physiology that needs to be further investigated.

Here, we provide direct evidence of serine proteases as active digestive enzymes

354 that can break down blood proteins. Future experiments will include the use of

355 recombinant I. scapularis serine proteases for blood protein digestion assays in vitro.

356 This initial exploration examined the most prominent I. scapularis digestive enzymes,

357 which only included 3 out of a putative 63 serine proteases present in the genome [3]. In

358 future studies, a more expansive screen will yield additional information on the dynamics

359 of I. scapularis digestive enzymes important in blood digestion.

\section{CONCLUSIONS}


Most studies in ticks suggest that blood digestion occurs in the acidic environment

362 of midgut vesicles by the cathepsin-like peptidases in partially engorged ticks. In this

363 study, we show that the trypsin-like proteases may play a significant role in blood protein

364 breakdown in fully engorged, replete ticks. One of the major advantages of characterizing

365 the serine proteases that regulate blood digestion is that they are generally secreted in the

366 extracellular environment and hence they are likely to be exposed to host antibodies

$367[29,30]$, making them suitable for anti-tick vaccine candidates.

AVAILABILITY OF DATA AND MATERIALS

All data generated or analyzed during this study are included in this published

371 article. The midgut RNASeq datasets used during the current study for identification of

372 serine proteases are available from the corresponding author on request.

\section{FUNDING}

This work was funded in part through an NIH R21AI128393 grant.

\section{AUTHOR CONTRIBUTION}

MGN and AN conceived the project and designed the experiments. JR carried out

377 RT-PCR work. CAC and JR did the active trypsin assay. JR did RNAi, densitometry and

378 statistical analysis. MP, AS, and JR carried out hemoglobin degradation and trypsin

379 inhibitor assays. AS performed statistical analysis. AN and MGN wrote the manuscript.

\section{CONFLICT of INTEREST}

We declare no conflict of interest. 


\section{REFERENCES}

385 1. Sonenshine, D.E. Biology of Ticks Volume 1; 1992; pp. 122-157.

2. Gulia-Nuss, M; Nuss, A.B.; Meyer, J.M., Sonenshine, D.E., Roe, R.M.;

Waterhouse, R.M.; Sattelle, D.B.; Fuente, J.; Ribeiro, J.M.; Megy, K.;

Thimmapuram, J.; Miller, J.R.; Walenz, B.P., Koren, S.; Hostetler, J.B.;

Thiagarajan, M.; Joardar, V.S.; Hannick, L.I.; Bidwell, S.; Hammond, M.P.;

Young, S.; Zeng, Q.; Abrudan, J.L.; Almeida, F.C.; Ayllón, N.; Bhide, K.;

Bissinger, B.W.; Bonzon-Kulichenko, E.; Buckingham, S.D.; Caffrey, D.R.;

Caimano, M.J.; Croset, V.; Driscoll, T.; Gilbert, D.; Gillespie, J.J.; Giraldo-

Calderón, G.; Grabowski, J.M.; Jiang, D.; Khalil, S.M.S.; Kim, D.; Kocan, K.M.;

Koči, J.; Kuhn, R.J.; Kurtti, T.J.; Lees, K.; Lang, E.G.; Kennedy, R.C.; Kwon, H.;

Perera, R.; Qi, Y.; Radolf, J.D.; Sakamoto, J.M.; Sánchez-Gracia, A.; Severo,

M.S.; Silverman, N.; Šimo, L.; Tojo, M.; Tornador, C.; Van Zee, J.P.; Vázquez,

J.; Vieira, F.G.; Villar, M.; Wespiser, A.R.; Yang, Y.; Zhu, J.; Arensburger, P.;

Pietrantonio, P.V.; Barker, S.C.; Shao, R.; Zdobnov, E.M.; Hauser, F.;

Grimmelikhuijzen, C.J.P.; Park, Y.; Rozas, J.; Benton, R.; Pedra, J.H.F.; Nelson, 
the Ixodes scapularis tick vector of Lyme disease. Nature Comm. 2016. DOI:

404 10.1038/ncomms 10507 .

3. Mulenga, A.; Erikson, K. A. Snapshot of the Ixodes scapularis degradome. Gene 2011, 482, 78-93, doi:10.1016/j.gene.2011.04.008.

4. Puente, X.S.; Sanchez, L.M.; Gutierrez-Fernandez, A.; Velasco, G.; Lopez-Otin, C. A. Genomic view of the complexity of mammalian proteolytic systems. Biochem. Soc. Trans. 2005, 33, 331-334, doi:10.1042/bst0330331.

5. Page, M.J.; Di Cera, E. Serine peptidases: Classification, structure and function. Cell. Mol. Life Sci. 2008, 65, 1220-1236, doi:10.1007/s00018-008-7565-9.

6. Santiago, P.B.; de Araujo, C.N.; Motta, F.N.; Praca, Y.R.; Charneau, S.; Dourado Bastos, I.M.; Santana, J.M. Proteases of haematophagous arthropod vectors are

7. Sojka, D.; Franta, Z.; Horn, M.; Hajdusek, O.; Caffrey, C.R.; Mares, M.; reveals an evolutionarily conserved network of aspartic and cysteine peptidases.

8. Horn, M.; Nussbaumerova, M.; Sanda, M.; Kovarova, Z.; Srba, J.; Franta, Z.; 
425 9. Calvo, E.; Pham, V.M.; Ribeiro, J.M.C. An insight into the sialotranscriptome of 426 the non-blood feeding Toxorhynchites amboinensis mosquito. Insect Biochem Mol Biol 2008, 38, 499-507, doi:10.1016/j.ibmb.2007.12.006.

10. Rascón, A. A.; Jr, Gearin, J.; Isoe, J.; Miesfeld, R. L. In vitro activation and enzyme kinetic analysis of recombinant midgut serine proteases from the Dengue

11. Gulia-Nuss, M.; Robertson, A. E.; Brown, M. R.; Strand, M. R. Insulin-like peptides and the target of rapamycin pathway coordinately regulate blood digestion and egg maturation in the mosquito Aedes aegypti. PloS one, 2011.

12. Sharma, A.; Pooraiiouby, R.; Guzman, B.; Vu, P.; Gulia-Nuss, M.; Nuss, A.B. 6(5), e20401. doi:10.1371/journal.pone.0020401

13. Hayakawa, T.; Kondo, T.; Yamazaki, Y.; Linuma, Y.; Mizuno, R. Gastroenterol 440 Jpn 1980, 15: 135. https://doi.org/10.1007/BF02774926

14. Sorgine, MH.; Logullo, C.; Zingali, RB.; Paiva-Silva, GO.; Juliano, L.; Oliveira, PL. J. A Heme-binding Aspartic Proteinase from the Eggs of the Hard Tick Boophilus microplusBiol. Chem. 2000, 275, 28659-28665. doi:10.1074/jbc.M005675200 
445 15. Felix, C. R.; Betschart, B.; Billingsley, P. F.; and Freyvogel, T. A. (1991) Post-

446

447

448

449

450

451

452

453

454

455

456

457

458

459

460

feeding induction of trypsin in the midgut of Aedes aegypti L. (Diptera:

Culicidae) is separable into two cellular phases. Insect Biochem. 21, 197 - 203.

16. Lara, F.A.; Lins, U.; Bechara, G.H.; Oliveira, P.L. Tracing heme in a living cell: hemoglobin degradation and heme traffic in digest cells of the cattle tick Boophilus microplus. J Exp Biol 2005, 208, 3093-3101, doi:10.1242/jeb.01749.

17. Ribeiro, J. M. The midgut hemolysin of Ixodes dammini (Acari: Ixodidae). J. Parasitol. 1988. 74, 532-537.

18. Mulenga, A.; Sugimoto, C.; Ingram, G.; Ohashi, K.; Misao, O. Characterization of two cDNAs encoding serine proteinases from the hard tick Haemaphysalis longicornis. Insect Biochem Mol Biol 2001, 31, 817-825, doi:10.1016/s09651748(00)00187-9.

19. Miyoshi, T.,; Tsuji, N.,; Islam, MK.; Huang, X.; Motobu, M.; Alim, MA.; Fujisaki, K. Molecular and reverse genetic characterization of serine proteinaseinduced hemolysis in the midgut of the ixodid tick Haemaphysalis longicornis. $\mathbf{J}$ Insect Physiol. 2007 Feb;53(2):195-203. doi: 10.1016/j.jinsphys.2006.12.001

20. Miyoshi, T.; Tsuji, N.; Islam, MK.; Alim, MA.; Hatta, T.; Huang, X.; Fujisaki, K. A set of serine proteinase paralogs are required for blood-digestion in the ixodid tick Haemaphysalis longicornis. Parasitol Int. 2008 Dec;57(4):499-505. doi:10.1016/j.parint.2008.08.003 
465 21. Hughes, T. E. (1954). Some histological changes which occur in the gut epithelium of Ixodes ricinus females during gorging and up to oviposition. Ann. trop. Med. Parasit. 48, 397-404.

22. Perner, J.; Provazník, J.; Schrenková, J.; Urbanová, V.; Ribeiro, JM.; Kopáček, P. RNA-seq analyses of the midgut from blood- and serum-fed Ixodes ricinus ticks.

23. Nepomuceno, D.B.; Santos, V.C.; Araujo, R.N.; Pereira, M.H.; Sant'Anna, M.R.; Moreira, L.A.; Gontijo, N.F. pH control in the midgut of Aedes aegypti under different nutritional conditions. J Exp Biol 2017, 220, 3355-3362, doi:10.1242/jeb.158956.

474 24. Erban, T.; Hubert, J. Determination of $\mathrm{pH}$ in regions of the midguts of acaridid 475 mites. J Insect Sci 2010, 10.

476 25. Brune, A.; Emerson, D.; Breznak, J.A. The termite gut microflora as an oxygen sink - microelectrode determination of oxygen and ph gradients in guts of lower and higher termites. Appl Environ Microbiol 1995, 61, 2681-2687.

479 26. Harrison, J.F. Insect acid-base physiology. Annu Rev Entomol 2001, 46, 221-250, doi:10.1146/annurev.ento.46.1.221.

481 27. Zimmer, M.; Brune, A. Physiological properties of the gut lumen of terrestrial isopods (Isopoda : Oniscidea): adaptive to digesting lignocellulose? J Comp Physiol B 2005, 175, 275-283, doi:10.1007/s00360-005-0482-4. 
484 28. Gross, E.M.; Brune, A.; Walenciak, O. Gut pH, redox conditions and oxygen 485 levels in an aquatic caterpillar: Potential effects on the fate of ingested tannins. J Insect Physiol 2008, 54, 462-471, doi:10.1016/j.jinsphys.2007.11.005.

487 29. Benyakir, D. Quantitative studies of host immunoglobulin-g in the hemolymph of 488 ticks (Acari). J Med Entomol 1989, 26, 243-246, doi:10.1093/jmedent/26.4.243.

489 30. Kerlin, R.L.; Allingham, P.G. Acquired immune-response of cattle exposed to 490 buffalo fly (Haematobia irritans exigua). Vet Parasitol 1992, 43, 115-129, 491 doi:10.1016/0304-4017(92)90054-d.

492

493

494

495

496

497

498

499

500

501

502

503 


\section{$507 \quad$ Figure Legends}

scapularis. A: Representative RT-PCR of ten I. scapularis proteases that belong to

different families was carried out at different time points during blood feeding and

digestion. Total RNA was extracted from a pool of 2-4 midguts at each time point and an

equal amount of cDNA was used for RT-PCR. B: The BioRad Gel Doc EZ Images were

used to determine concentrations of PCR product in each lane across the gel for each

514 gene. The ratio of concentrations of the protease and tubulin (housekeeping gene) PCR

515 products were calculated. After calculating the ratios, the band with highest expression

516 in each gene was set at 1 and the values were determined accordingly and plotted to

517 accurately depict the change in expression of each gene over time. UF= unfed female

518 midgut, $\mathrm{PE}=$ partially engorged (females were pulled from the host 5 days post

519 attachment), PBM= post blood meal (fully engorged females dropped off the host). SP=

520 serine protease; LAP= Leucine Aminopeptidase

521 Figure 2: Trypsin activity in developmental stages and adult female. Trypsin activity

522 was measured by the BApNA assay in unfed and blood fed ticks. A: Larvae and B:

523 Nymphs were fed on a mouse and engorged larvae or nymphs that dropped off the host

524 were collected. Whole body of larvae and nymphs were homogenized for the assay.

525 Unfed larvae and nymphs were used as a control. C: Adult females were fed on a rabbit. 
526 Females were either pulled off the host 5 days post attachment (partially engorged) or

527 fully engorged females that dropped off the host were collected over several days.

528 Midguts were dissected and washed for determination of trypsin activity. Unfed female

529 midguts were used as a control. One-way ANOVA and Dunnet's multiple comparison

530 were used for statistical analysis. $*=0.01 ; * *=0.001 ; * * *=0.0001$

531 Figure 3: Effect of serine protease knockdown on tick feeding, blood digestion,

532 survival, and reproduction. A: Representative RT-PCR of three I. scapularis serine

533 proteases. C: control ticks injected with water, RNAi: dsRNA injected ticks. SP: serine

534 protease, SP1=ISCW021184, SP2=ISCW006427, and SP4=ISCW007492. B: Wet weight

535 of ticks measured immediately after dropping off host. C: Percent mortality after

536 infesting the rabbit. Dead females were counted daily until all dropped off. The percent

537 dead ticks were calculated by combining the numbers from Day-0 (on the rabbit) until

538 day-10 (all females dropped off). D: Egg clutch weight. Replete ticks were kept

539 individually in an incubator. Number of eggs deposited each day was counted and egg

540 clutch was weighed once females stopped laying eggs for 2 consecutive days. E: Active

541 trypsin levels were measured by the BApNA assay in guts dissected from replete

542 females, one day post host drop off. Unpaired t test with Welch`s correction was used for

543 comparing control and a treatment (SP1, SP2 and SP4) using Graphpad Prism v8. The

544 confidence interval was $95 \%$ and significance level was fixed @ $\mathrm{p}<0.05 . * * * \mathrm{P}<0.0001$

545

546 Figure 4: Hemoglobin degradation by gut extract. A. Gut tissue was dissected from

547 fully engorged tick females (day 1 post repletion and drop off), washed from the gut

548 contents and protein was extracted. Bovine hemoglobin was incubated with either control 
or SP1, SP2, and SP4 knockdown gut protein extracts. The relative rate of degradation of the substrate was determined using the measurement of fluorescence in a hemoglobinolytic assay. Aliquots of samples were taken over the course of 30 minutes and quantified using fluorescamine. Values are normalized to the fluorescence intensity at time $0 \mathrm{~min}$ and presented in absorbance units (A.U.). The error bars indicate standard deviations of the mean of triplicates. B. Peptidolytic activities in the gut tissue extract of fully engorged tick females was demonstrated in vitro. Bovine hemoglobin (Hb) was incubated with bovine trypsin or control gut sample. For serine protease inhibition assay, gut extract or bovine trypsin were pre-incubated with serine protease inhibitor PMSF before adding hemoglobin. Aliquots of samples were taken over the course of 30 minutes and quantified using fluorescamine. Values are normalized to the fluorescence intensity at time 0 min and presented in absorbance units (A.U.). The error bars indicate standard deviations of the mean of triplicates. Each treatment was compared with control for each timepoint using unpaired t test with Welch`s correction with $95 \%$ confidence interval and $\mathrm{p}<0.05 . *=\mathrm{p}<0.05 ; * *=\mathrm{p}<0.01, * * * \mathrm{p}<0.0001$

\section{Figure 5: Proposed model of blood digestion in replete females. We suggest that} existing model is correct for partially engorged females; however, we propose a new model for replete females. In this model, we suggest that ingested blood proteins are digested in the gut lumen where higher $\mathrm{pH}$ is suitable for trypsin-like enzymes. Degraded peptides might then be taken into endosomes of digestive cells where low $\mathrm{pH}$ allows catalysis by cathepsins and other proteases that are active at acidic $\mathrm{pH}$, eventually breaking the peptides into dipeptides or free amino acids. 
Figure 1

A

\begin{tabular}{|c|c|c|c|c|c|c|c|}
\hline & & \multicolumn{5}{|c|}{ Timepoints } & \\
\hline Gene & Accession ID & UF & 1D PBM & 2D PBM & 7D PBM & 14D PBM & Size (bp) \\
\hline Cathepsin D & ISCW023880 & & & & & & 504 \\
\hline Cathepsin L & ISCW024899 & & & & & & 210 \\
\hline Cathepsin L & ISCW000076 & & & & & & 182 \\
\hline Legumain & ISCW015983 & & & & & & 432 \\
\hline Cathepsin C & ISCW003494 & & & & 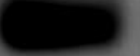 & & 308 \\
\hline Serine Protease 1 & ISCW021184 & 1 & & & & & 382 \\
\hline Serine Protease 2 & ISCW006427 & . & & & & & 397 \\
\hline Serine Protease 3 & ISCW010371 & & & & & & 512 \\
\hline Serine Protease 4 & ISCW007492 & & & $2=$ & $=$ & & 581 \\
\hline Leucine Aminopeptidase & ISCW023735 & & & & & & 714 \\
\hline Tubulin (Control) & ISCW005137 & & & & & & 107 \\
\hline
\end{tabular}


B

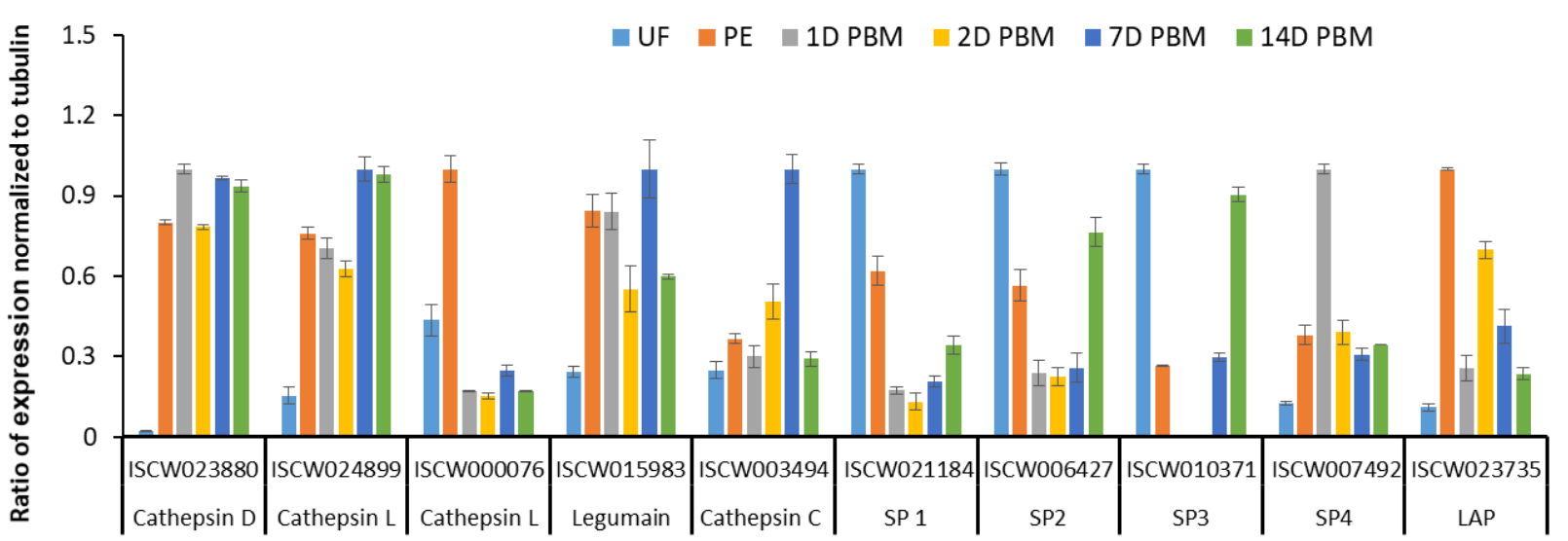

581 
$582 \quad$ Figure 2

A

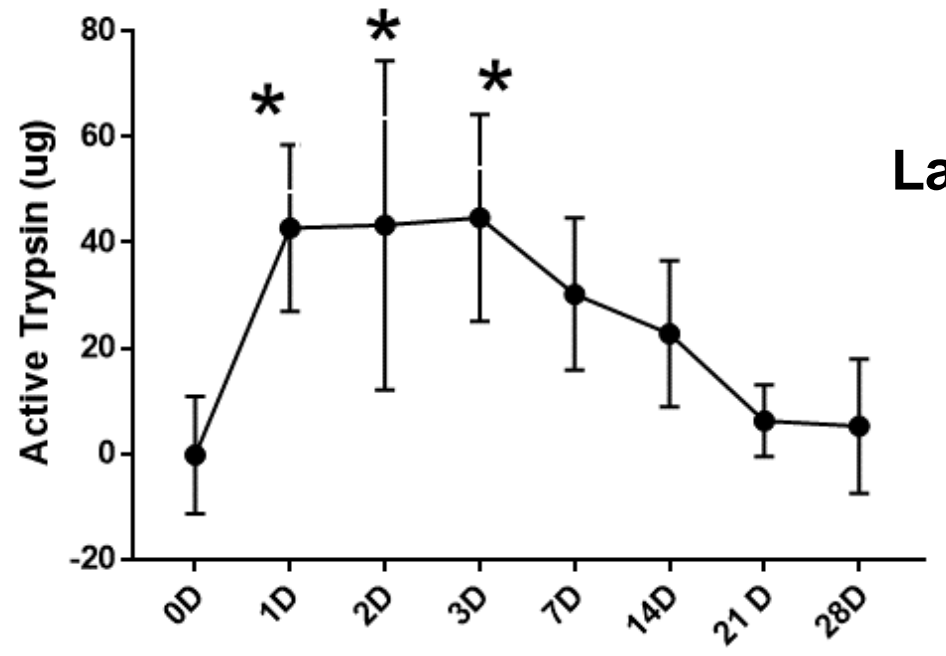

B

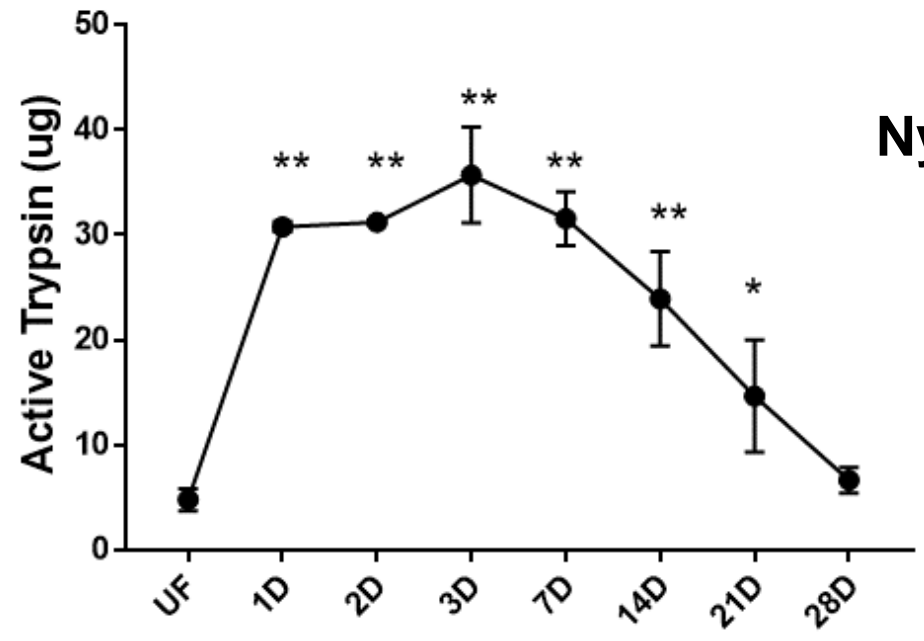

C

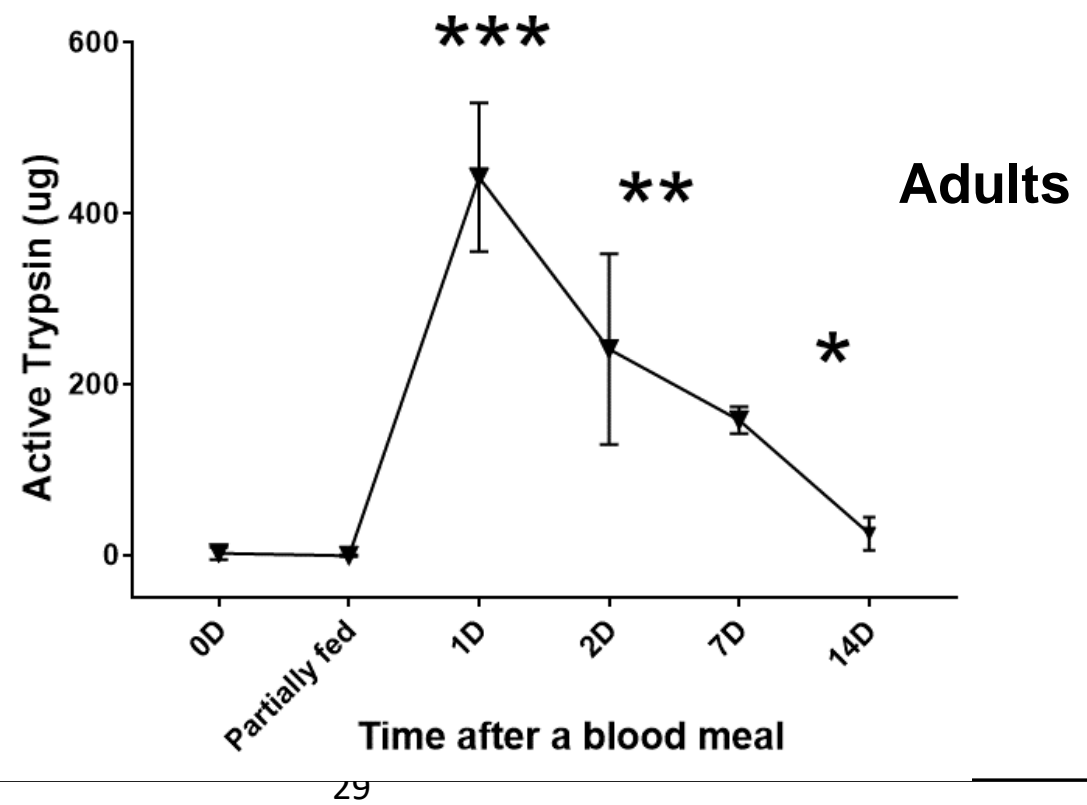




\section{$583 \quad$ Figure 3}

$584 \quad$ A

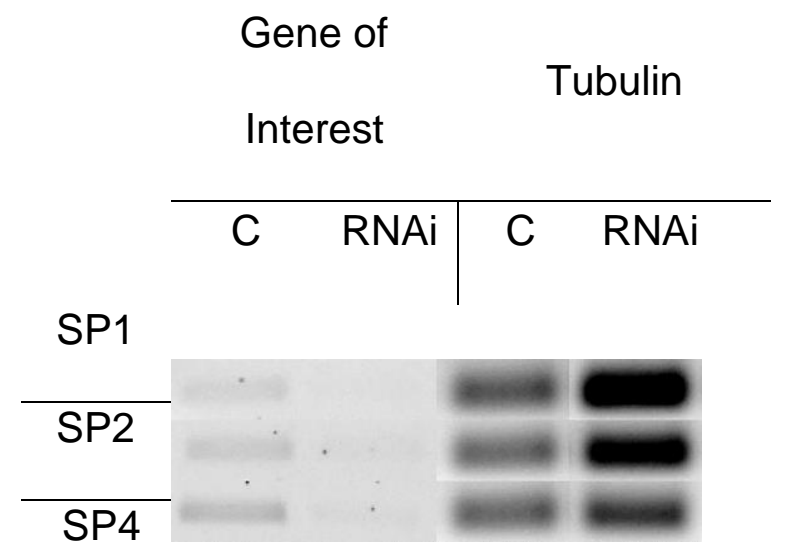

585

586

587 B

588

589

590

591

592

593

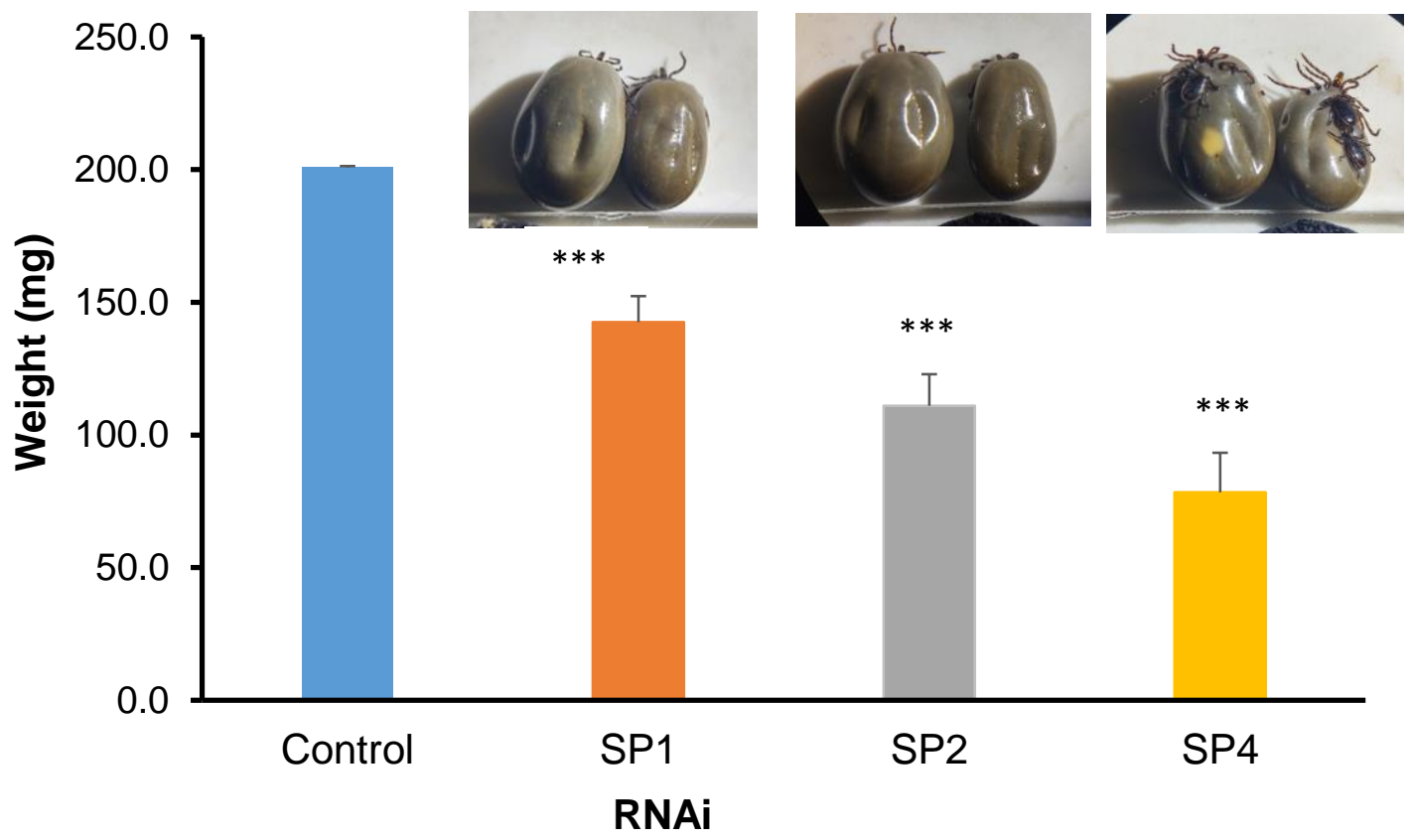

594

595

596 
597

C

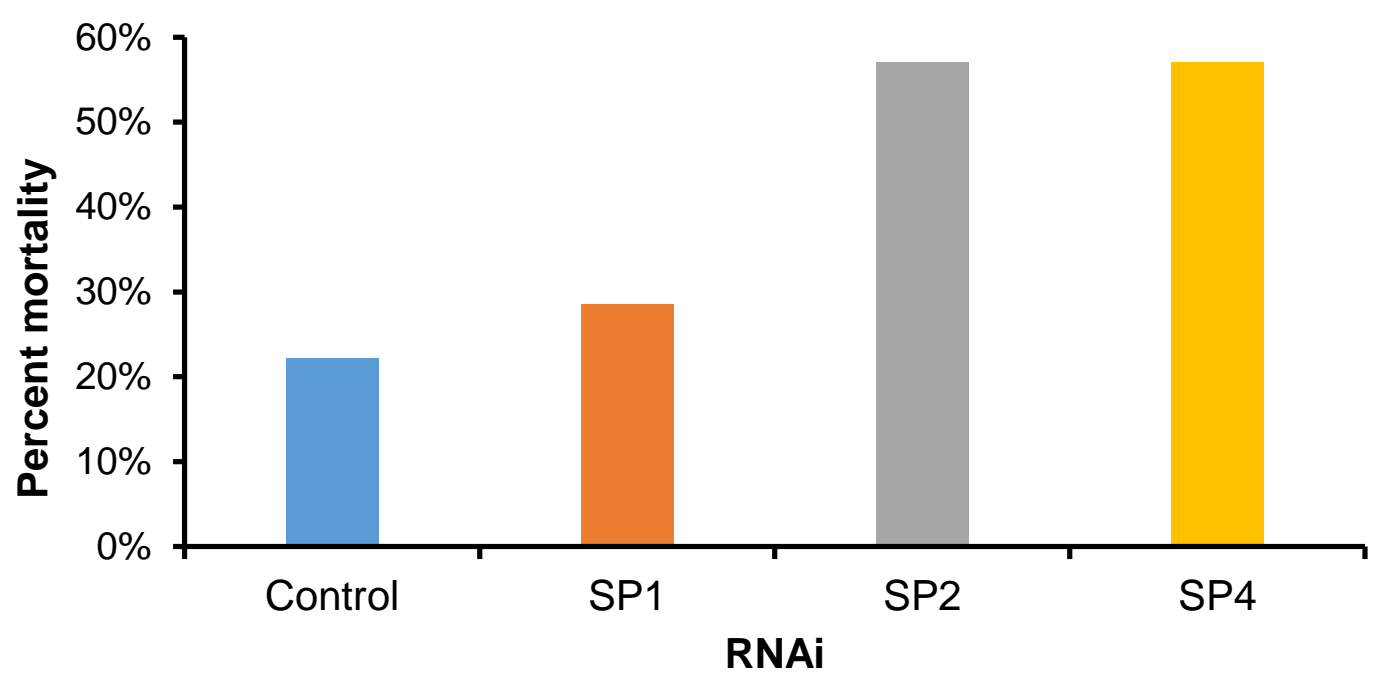

598

599

600 D

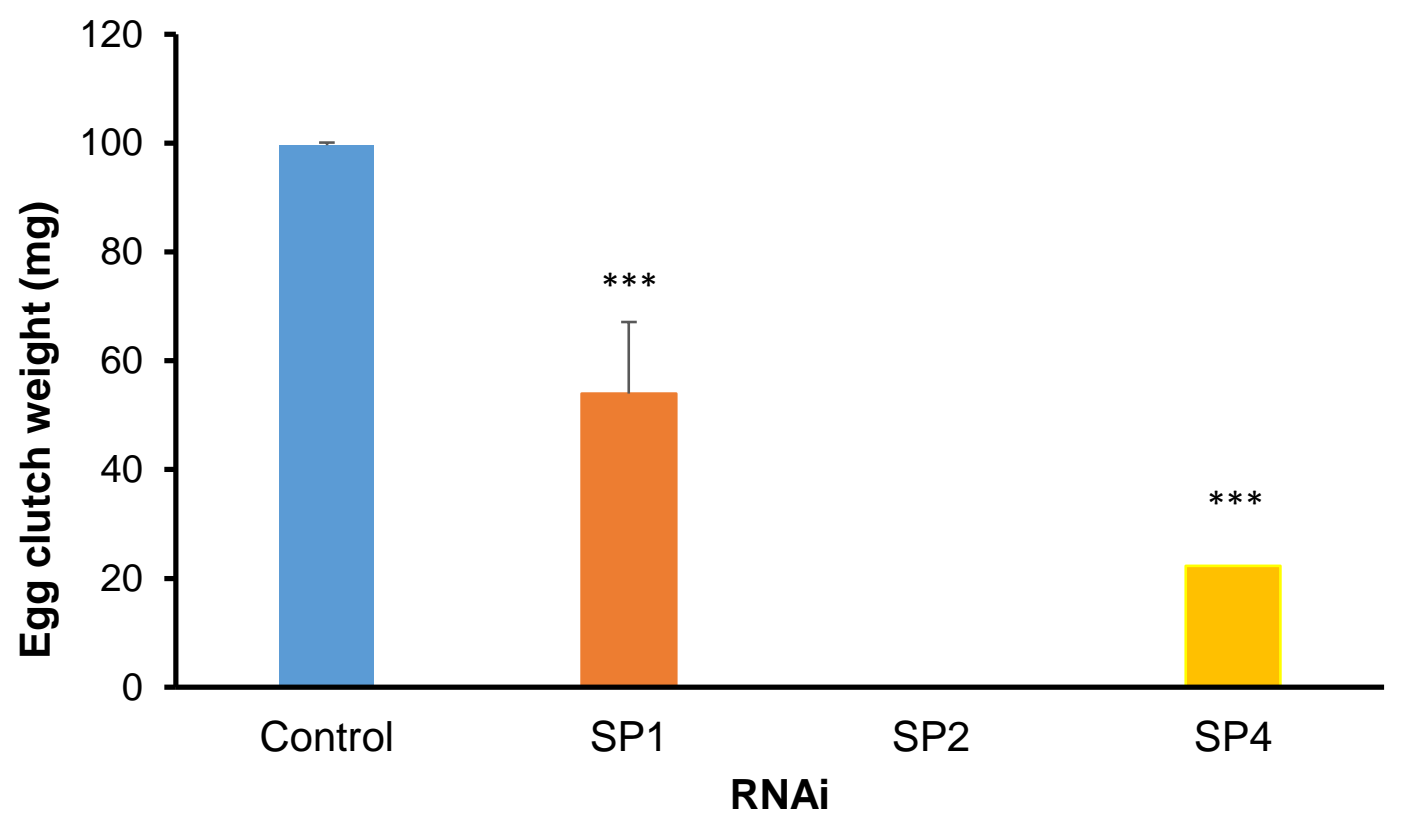

601

602 
603 E

604

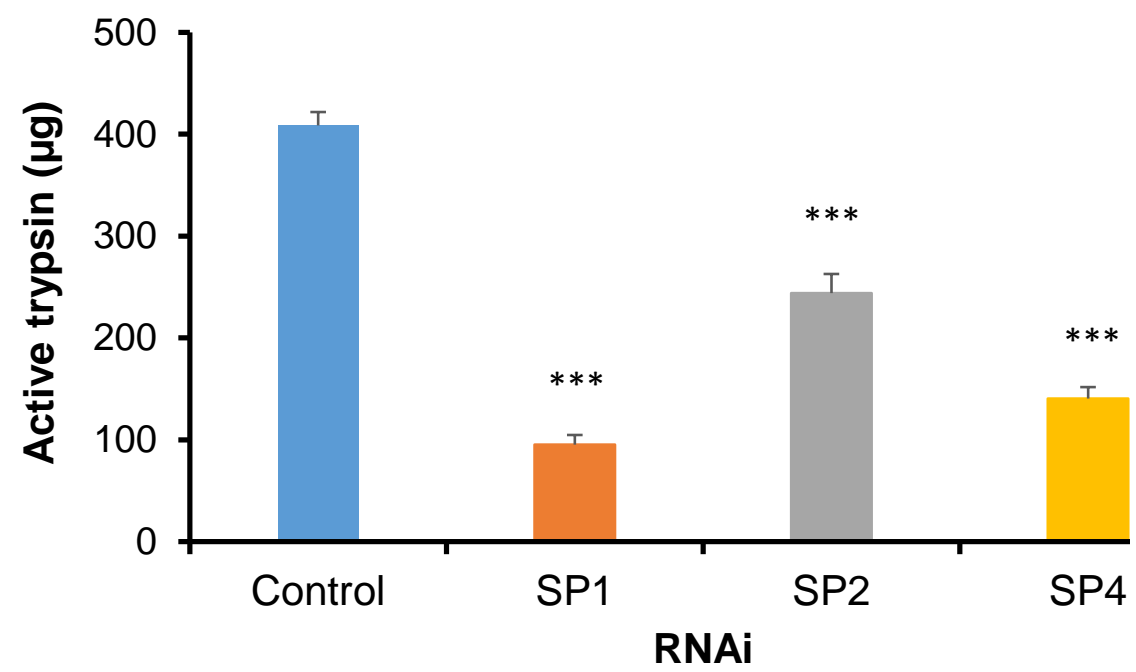

611

612

613

614

615

616

617

618

619

620 


\section{$621 \quad$ Figure 4}

622 A

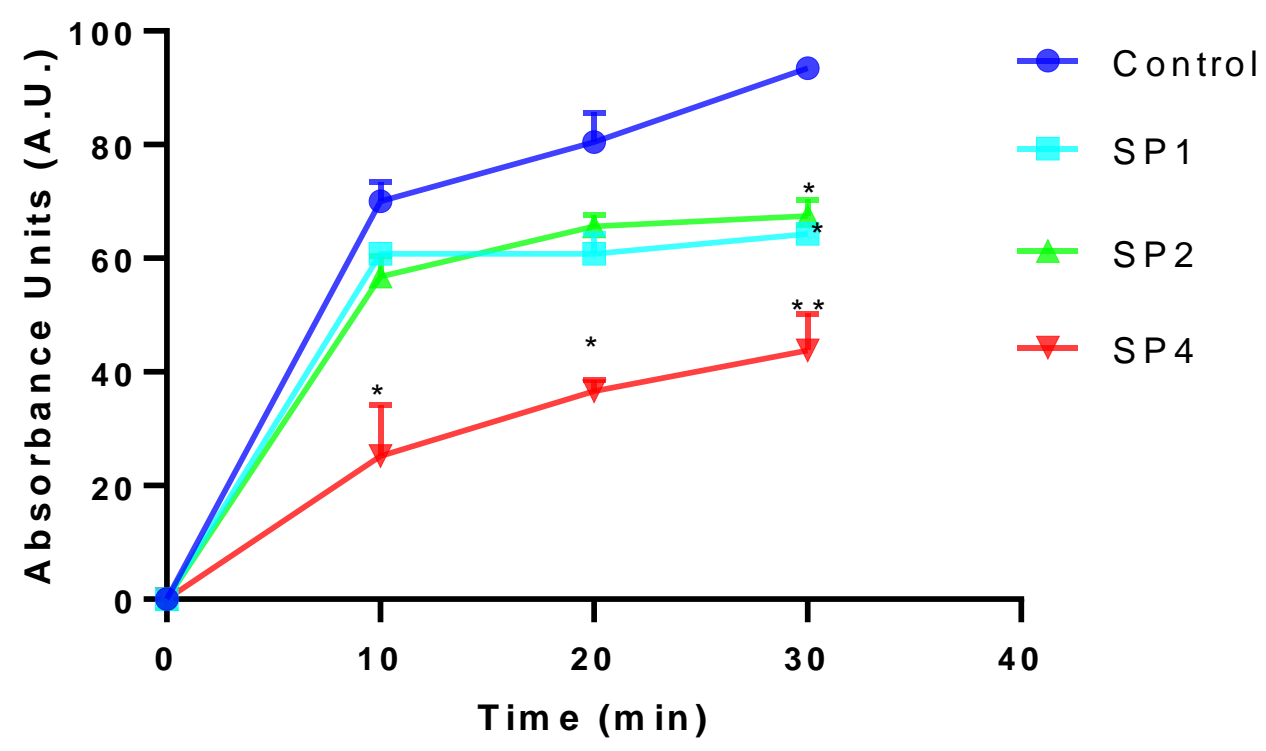

623

624

625 B

626

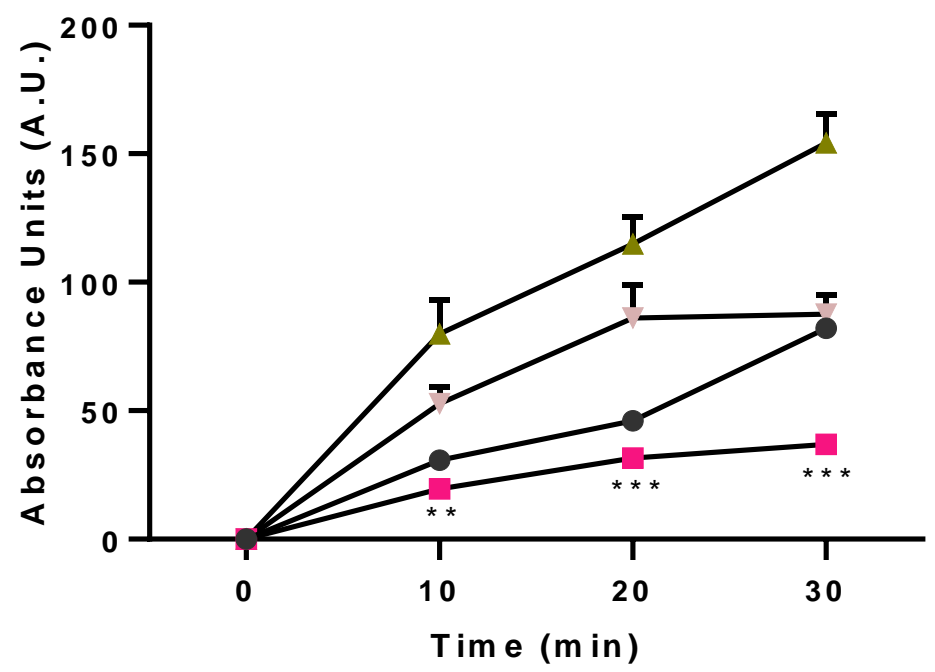

$$
\begin{aligned}
& - \text { Trypsin } \\
& - \text { Trypsin +PMSF } \\
& \rightarrow \text { Gut Extract } \\
& - \text { Gut Extract+ PMSF }
\end{aligned}
$$




\section{$628 \quad$ Figure 5}
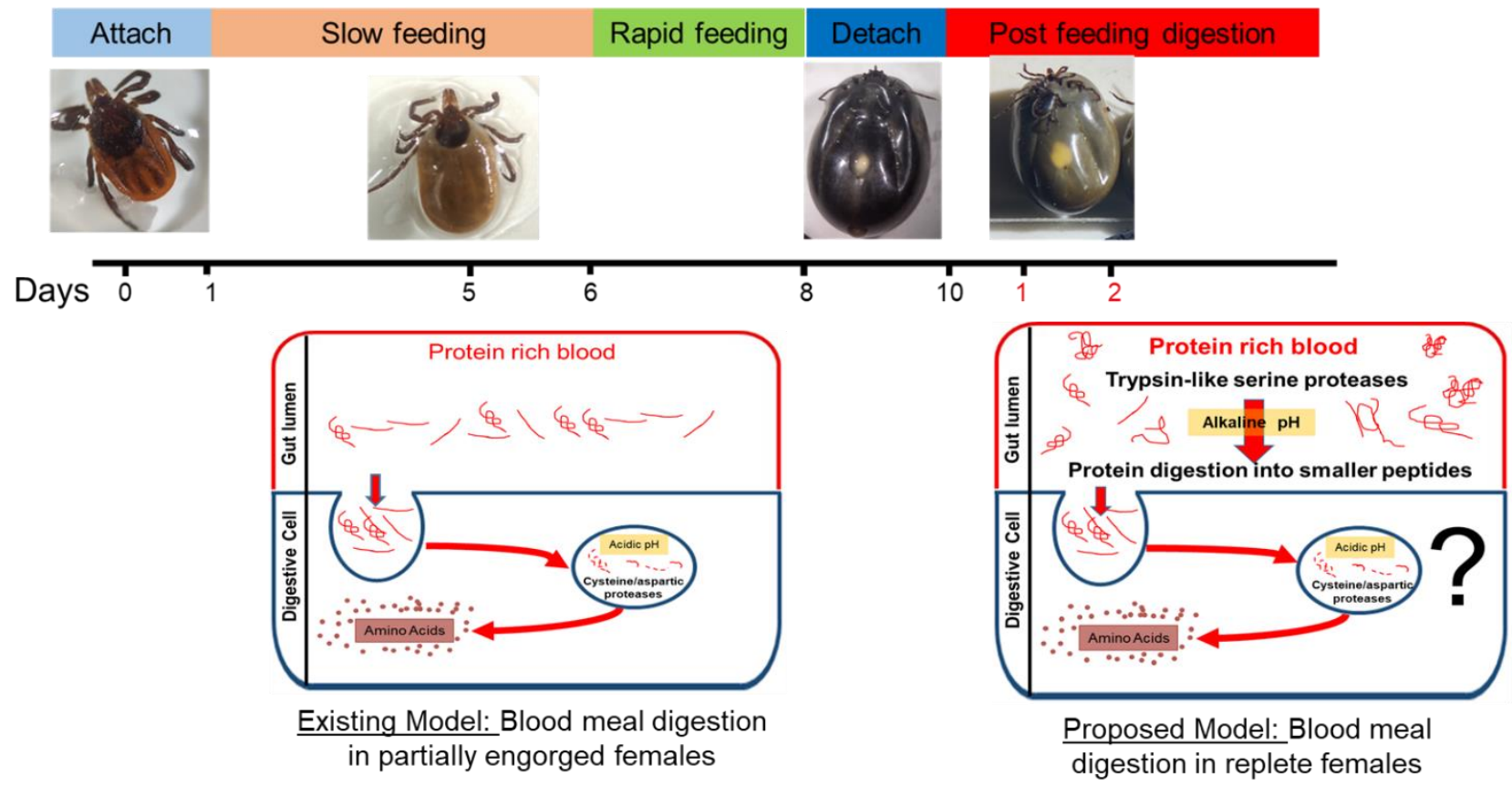

630

631

632

633

634

635

636

637

638

639 
640 Table 1: A list of primer pairs and the annealing temperature used for each primer pair.

\begin{tabular}{|c|c|c|}
\hline Gene Name and Accession Number & Primer Pair Sequence & Annealing Temp ${ }^{\circ} \mathrm{C}$ \\
\hline $\begin{array}{c}\text { Cath D (Aspartic) } \\
\text { ISCW023880/XM_002416473.1 }\end{array}$ & & \\
\hline $\begin{array}{l}\text { IscapCathDFwd } \\
\text { IscapCathDRev }\end{array}$ & $\begin{array}{c}\text { CCCTTCCGTGTGGTGTTTG } \\
\text { AGTAGCCCTTGGTTGAGACAG }\end{array}$ & 55 \\
\hline $\begin{array}{c}\text { Cath L (Cysteine) } \\
\text { ISCW024899/XM_002416305.1 }\end{array}$ & & \\
\hline $\begin{array}{r}\text { IscapCathLFwd } \\
\text { IscapCathLRev }\end{array}$ & $\begin{array}{l}\text { GACTTCCAGATGTACCAGGGC } \\
\text { GAAGGATGCGGAAGTAGCCG }\end{array}$ & 55 \\
\hline $\begin{array}{c}\text { Cath L (Cysteine) } \\
\text { ISCW000076/ XM_002404428.1 }\end{array}$ & & \\
\hline $\begin{array}{r}\text { IscapCathL2Fwd } \\
\text { IscapCathL2Rev }\end{array}$ & $\begin{array}{l}\text { AAGTGGCCCCACTGCAACTC } \\
\text { TTACCCGTAACCGCAGGAATG }\end{array}$ & 55 \\
\hline $\begin{array}{c}\text { Legumain (Apartic) } \\
\text { ISCW015983/XM_002402043.1 }\end{array}$ & & \\
\hline $\begin{array}{c}\text { IscapLegumainFwd } \\
\text { IscapLegumainRev }\end{array}$ & $\begin{array}{c}\text { CCCCTGGAGTGGTCATCAAC } \\
\text { TAAGTGTTTCGGAGGGCGTC }\end{array}$ & 55 \\
\hline $\begin{array}{c}\text { Cath C (Cysteine) } \\
\text { ISCW03494/ XM_002400742.1 }\end{array}$ & & \\
\hline $\begin{array}{l}\text { IscapCathCFwd } \\
\text { IscapCathCRev }\end{array}$ & $\begin{array}{c}\text { CGTTAACTACGTGTCCCCTG } \\
\text { TAGTTGCCGACGTAATGCC }\end{array}$ & 57 \\
\hline $\begin{array}{c}\text { Serine Protease } 1 \\
\text { ISCW021184/ XM_002405400.1 }\end{array}$ & & \\
\hline IscapSP1Rev & $\begin{array}{l}\text { AGCCTAATCAATCAAGGGCG } \\
\text { GACCAGTTTAGGGATGCGAG }\end{array}$ & 58 \\
\hline
\end{tabular}




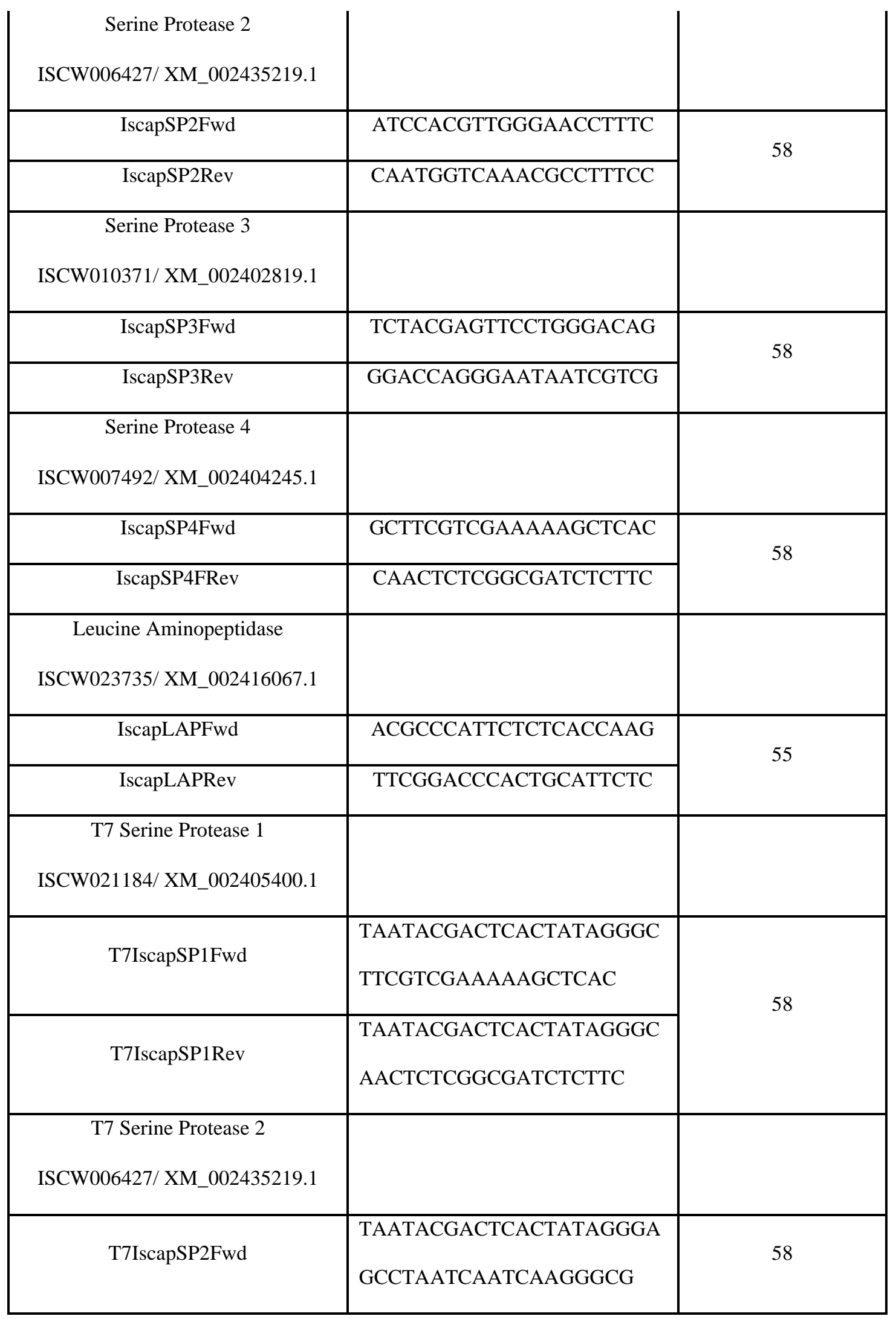


Peer-reviewed version available at Insects 2020, 11, 201; doi:10.3390/insects11030201

\begin{tabular}{|c|l|l|} 
T7IscapSP2Rev & TAATACGACTCACTATAGGGA & \\
\hline T7 Serine Protease 4 & CCAGTTTAGGGATGCGAG & \\
\hline ISCW007492/ XM_002404245.1 & & \\
\hline T7IscapSP4Fwd & TAATACGACTCACTATAGGGA & \\
\hline T7IscapSP4FRev & TCCACGTTGGGAACCTTTC & \\
\hline Tubulin & TAATACGACTCACTATAGGGC & \\
\hline IscapB-TubRev & AATGGTCAAACGCCTTTCC & \\
\hline ISCW005137/ XM_002402966.1 & GCAAAGCTGTTCAAGCCTCT & \\
\hline & & \\
\hline & & \\
\hline
\end{tabular}

641 